\title{
Training and education model for anatomy near-peer teachers
}

\author{
Francisco D. Guerrero-Mendivil, Milton A. Muñoz-Leija, Alejandro Quiroga-Garza*, \\ David de la Fuente-Villarreal, Guillermo Jacobo-Baca, Jorge Gutiérrez-de la O, \\ Rodrigo E. Elizondo-Omaña, and Santos Guzmán-López \\ Department of Human Anatomy, School of Medicine, Universidad Autónoma de Nuevo León, Monterrey, Nuevo Leon, Mexico
}

\section{Introduction}

Peer-assisted learning (PAL) has been defined as "people from similar social groupings who are not professional teachers, helping each other learn, and learning themselves by teaching"1. One method of applying PAL is having senior students acting as instructors to junior students, called near-peer teaching ${ }^{2}$, where the "teacher" is 2-5 years more experienced than the student ${ }^{3}$.

The use of near-peer teachers (NPTs) for student education has well-documented benefits at different levels. For the institution, it can lighten the faculty teaching burden and accommodate the increasing number of medical students in pre-clinical years ${ }^{4}$. The students, or near-peer learners (NPLs), feel confident and relaxed with the less formal atmosphere, stimulating interaction between them and the NPT ${ }^{5}$. They also share a similar knowledge base and learning experience, known as "cognitive congruence" and a "social congruence" due to their similar social roles ${ }^{6}$. The NPT enhances their learning through teaching ${ }^{7}$ and develops communication, leadership, organizational, and group facilitation skills that may not be included in formal medical curricula ${ }^{4,8,9}$.

It has been reported that the most common roles perceived by NPTs are information providers, role models, and facilitators, and they are less likely to be seen as a resource developer or planner ${ }^{5}$. However, it has been reported that these roles might vary according to the NPT activities they are involved in². Consequently, it can be asserted that tutor training should develop both teaching skills and content-specific knowledge ${ }^{10}$.

Most studies focus on the outcome effects of NPT, with few specifying their training programs. Publications vary in content, but most programs are focused on teaching/facilitation skills and content-specific knowledge $^{9,11,12}$, assessment and feedback techniques ${ }^{13}$, or teaching/facilitation skills training only in clinical or procedural skills ${ }^{14,15}$. Detailed descriptions of anatomy NPT training are lacking. This report aims to describe the education and training implemented on the NPT in a human anatomy course and the methods applied to create motivation and commitment.

\section{Anatomy course}

The Human Anatomy Department of the School of Medicine, in the Universidad Autonoma de Nuevo Leon (UANL), is responsible for coordinating the course of Gross Human Anatomy. The subject is imparted during the second semester of a 12-semester program. The school enrolls over 1000 students each semester.

The course is taught over 19 weeks, imparted through a theoretical and a practical (laboratory) approach. The theoretical classes consist of daily 1 -h sessions with interactive discussions and active participation between a professor, two NPT, and 30-35 students per

\section{Correspondence:}

*Alejandro Quiroga-Garza

E-mail: dr.aquirogag@gmail.com

uirogag@gmail.com DOI: 10.24875/RMU.20000045

1665-5796/@ 2020 Universidad Autónoma de Nuevo

(http://creativecommons.org/licenses/by-nc-nd/4.0/).
Date of reception: 16-05-2020

Date of acceptance: 05-08-2020
Available online: $24-12-2020$

Medicina Universitaria. 2020;22(4):176-179 www.medicinauniversitaria.org access article under the CC BY-NC-ND license 
group. An extra 1-h weekly introductory session is also given to integrating basic concepts with morphological diagnosis through clinical reasoning. Anatomical education within the medical school should have two main objectives: to acquire anatomical knowledge and develop clinical reasoning skills ${ }^{16}$. The latter is a term used to describe the mental processes associated with health-care provision, which includes a series of reasoning skills to make a diagnostic/therapeutic decision ${ }^{17}$. It is a central component of physician competence that should be taught and tested ${ }^{18}$.

Laboratory practices include three 1-h weekly sessions for clinical cases, imaging, and laboratory dissection/prossection. For these, class groups are broken down into small discussion groups between 5 and 6 students with one professor or NPT ${ }^{19}$. The learning benefits of small groups have been widely described. It promotes clinical reasoning and skills for lifelong learning $^{20-22}$. Other advantages are integrating students with the development of friendships, sharing ideas, dividing the workload, tutoring, and learning support from others, and communication skills. Benefits from the teacher's perspective include a potentially less stressful environment for new, international, or less social students to interact with their peers and a better quality of work $^{23}$.

NPT is also available for group or individual reviews/ lessons. Cadaveric dissection and technological resources represent different approaches to learning anatomy. However, integrating these methods should develop skills in the students that can be divided into three categories: theoretical, practical, and bioethical. The student learns clinical anatomy with the discussion of clinical cases and then integrates that anatomical knowledge with the clinical through technological resources (medical imaging techniques). With these acquired skills, the student gains practical knowledge in the anatomy laboratory with the cadaver, where a discussion regarding bioethical considerations of this practice should be encouraged ${ }^{24}$.

\section{NPT}

Due to the large number of students enrolled per semester, the active participation of NPTs is vital for the small-group dynamic teaching method ${ }^{19,25}$. The department has between 50 and 60 NPTs from different semesters enrolled in the program. After passing the gross anatomy course, students may apply to the NPT selection process. The requirements include a motive letter to the head of the department and an interview with a senior NPT. Depending on the needs of each semester, only approximately $20 \%$ of applicants are accepted.

Once accepted, their responsibilities depend on their seniority. Freshmen NPT (1-2 semesters) participates mainly in the classes. Sophomores and juniors (3-6 semesters) are responsible for the clinical cases and imaging sessions. It is important to mention that they are starting or going through the clinical years of their curricula, and therefore, they are familiar with the propaedeutic. Seniors ( $\geq 7$ semesters) oversee the prosections and dissections. All NPTs also have weekly training sessions with experienced professors, specialists, or fellow senior NPTs to prepare them for the upcoming activities of the following week and the most challenging topics ${ }^{26}$.

The following workshops are also made available each semester for NPTs, imparted by experts in their fields: advanced dissection, advanced suturing, laparoscopic anatomy, fundamentals of ultrasound, ultrasound-guided central venous catheterization, fundamentals of minimally invasive surgery, and virtual arthroscopy.

\section{Training and education}

The NPT training objective is providing near-peers with knowledge and skills. They develop educational and teaching skills during classes and training sessions and advanced anatomical knowledge through discussion, repetition, and teaching. Classes with students may be given and guided by the NPT, with surveillance by senior NPTs and professors for constructive feedback afterward. NPT-to-NPT and NPT-to-professor mentoring also develop with time, as collaboration is encouraged. They may support, educate, and encourage mentees into academic activities ${ }^{27}$. Training also includes a review of teaching and pedagogical techniques: appropriate control of the classroom, giving feedback, promoting the active participation of the students, and how to avoid mannerisms.

Training sessions are divided into two halves. In the first one, the clinical cases to be reviewed next week are discussed between NPTs and specialists from different fields (Surgery, Gynecology, Orthopedics, Sports Medicine, Radiology, Otorhinolaryngology, Ophthalmology, Neurosurgery, Neurology, Psychiatry, etc.), depending on the topic. These are usually former NPTs of the department. In the second half, radiological studies are reviewed to compare and discuss the anatomy and pathological findings. These are led by the professors from the radiology and diagnostic imaging department.

Cadaveric training for NPTs is also given, so they can then interact with students during prossection sessions 
and guide and supervise student dissections. Basic suturing skills are also taught by NPTs to students using sponges during laboratory practices. NPTs also help supervise the case-based examinations for both theory and practice during the semester.

\section{Payment with knowledge}

Where participation is voluntary, the intrinsic and extrinsic rewards may have considerable bearing on recruitment and retention of NPTs ${ }^{28}$. Voluntary integration helps to create a stress-free environment and avoids misconduct ${ }^{25}$. Evidence suggests the intrinsic rewards undermine the use of extrinsic rewards. Our department can only sponsor economic remunerations or scholarship to the 20 most senior and participative NPTs. However, other intrinsic rewards are provided.

A "payment with knowledge" method with the mentioned workshops and integration activities (social and sports activities) has helped motivate the NPT. The department head and senior professors sponsor some of the social activities or gatherings. The use of the department logo on uniforms for sports teams is allowed, created between the NPTs for extracurricular activities in the school, to which many professors and colleague NPTs assist and support during matches. NPTs are also provided with scholarly aid and tutoring when needed.

NPTs are generally satisfied, committed, and have a sense of belonging to the Department. At present, a Clinical Anatomy and Surgical Training diploma are being implemented as part of the "payment with knowledge" initiative. NPTs that invest seven semesters and complete 6 of the seven workshops offered and their NPT responsibilities will be awarded the diploma with curricular and educational value for their curriculum vitae and application to post-graduate programs.

\section{Future perspectives}

The use of near-peer teaching programs has long occurred informally in medical education over the last few decades. Skills are passed on from generation to generation. Most NPT are not teachers and have not had previous training in teaching skills ${ }^{4}$. Their activities include teaching new content, helping NPLs learn knowledge or clinical skills, or providing assessment with feedback. As the NPTs have less knowledge of the subject matter and less developed teaching skills than professors, their training should be focused on developing both teaching skills and content-specific knowledge ${ }^{10,29}$. Benefits for the institution, the NPTs, and the NPLs have been well-described ${ }^{4-6,8,9}$. However, there is insufficient evidence of objectively-measured improvement of the NPT on knowledge or academic performance ${ }^{30}$. Further studies are necessary to address this gap.

Institutions will benefit from formal and well-organized near-peer teaching programs and need to inspire a sense of belonging among their members ${ }^{4}$. The program should also be dynamic and adapt according to the experience the NPT obtains as more semesters are invested in the same department. At the UANL medical school, many of the basic and clinical sciences departments have implemented NPT programs to fit their needs. The duration of the program varies depending on the semester in which the course is taught.

\section{Conclusions}

NPTs are a valuable element in medical education. Their training should be formal and organized to succeed. It should not be static, but instead continually evolving, adapting to the new challenges created by emerging technological and educational advancements. The NPT training described has proven to be effective over the years, although future studies should objectively evaluate NPT perceptions regarding its effectiveness. The "payment with knowledge" method motivates NPTs and improves their performance. In further studies describing NPT experiences, authors should report a detailed description of their NPT training and education models, compare methodologies, and implement new strategies to improve near-peer teaching.

\section{Conflicts of interest}

The authors declare that they have no conflicts of interest.

\section{Funding}

The authors declare that they did not receive funding from any private or public organizations for the completion of this research.

\section{References}

1. Glynn LG, MacFarlane A, Kelly M, Cantillon P, Murphy AW. Helping each other to learn-a process evaluation of peer assisted learning. BMC Med Educ. 2006;6:18.

2. Reyes-Hernández CG, Pulido JM, Chapa RI, Vázquez RP, Briones RD, Banda PM, et al. Near-peer teaching strategy in a large human anatomy course: perceptions of near-peer instructors. Anat Sci Educ. 2015;8:189-93.

3. Hall S, Lewis M, Border S, Powell M. Near-peer teaching in clinical neuroanatomy. Clin Teach. 2013;10:230-5. 
4. Burgess A, McGregor D, Mellis C. Medical students as peer tutors: a systematic review. BMC Med Educ. 2014;14:115.

5. Bulte C, Betts A, Garner K, Durning S. Student teaching: views of student near-peer teachers and learners. Med Teach. 2007;29:583-90.

6. Yu TC, Wilson NC, Singh PP, Lemanu DP, Hawken SJ, Hill AG. Medica students-as-teachers: a systematic review of peer-assisted teaching during medical school. Adv Med Educ Pract. 2011;2:157-72.

7. Topping KJ. Trends in peer learning. Educ Psychol. 2005;25:631-45.

8. de Menezes S, Premnath D. Near-peer education: a novel teaching program. Int J Med Educ. 2016;7:160-7.

9. Nestel D, Kidd J. Peer assisted learning in patient-centred interviewing: the impact on student tutors. Med Teach. 2005;27:439-44.

10. Wadoodi A, Crosby JR. Twelve tips for peer-assisted learning: a classic concept revisited. Med Teach. 2002;24:241-4.

11. Elharram M, Dinh T, Lalande A, Ge S, Gao S, Noël G. Global health values of a multidirectional near peer training program in surgery, pathology, anatomy, research methodology, and medical education for Haitian, Rwandan, and Canadian medical students. Ann Glob Health. 2017;83 274-80.

12. Heckmann JG, Dütsch M, Rauch C, Lang C, Weih M, Schwab S. Effects of peer-assisted training during the neurology clerkship: a randomized controlled study. Eur J Neurol. 2008;15:1365-70.

13. Burgess A, Clark T, Chapman R, Mellis C. Senior medical students as peer examiners in an OSCE. Med Teach. 2013;35:58-62.

14. Silbert $\mathrm{BI}$, Lake FR. Peer-assisted learning in teaching clinical examination to junior medical students. Med Teach. 2012;34:392-7.

15. Weyrich P, Schrauth M, Kraus B, Habermehl D, Netzhammer N, Zipfel S, et al. Undergraduate technical skills training guided by student tutors-analysis of tutors' attitudes, tutees' acceptance and learning progress in an innovative teaching model. BMC Med Educ. 2008;8:18.

16. Quiroga-Garza A, Teran-Garza R, Elizondo-Omaña RE, Guzmán-López S The use of clinical reasoning skills in the setting of uncertainty: a case of trial femoral head migration. Anat Sci Educ. 2020;13:102-6.

17. Elizondo-Omaña RE, Morales-Gómez JA, Morquecho-Espinoza O, Hinojosa-Amaya JM, Villarreal-Silva EE, García-Rodríguez MD, et al. Teaching skills to promote clinical reasoning in early basic science courses. Anat Sci Educ. 2010;3:267-71.
18. Norman G. Research in clinical reasoning: past history and current trends. Med Educ. 2005;39:418-27.

19. Elizondo-Omaña RE, Quiroga-Garza A, Salinas-Alvarez YE, Guzman-Lopez S. Breaking down large anatomy groups. FASEB J. 2020;34:1.

20. Nathaniel TI, Gainey JC, Williams JA, Stewart BL, Hood MC, Brechtel LE, et al. Impact and educational outcomes of a small group self-directed teaching strategy in a clinical neuroscience curriculum. Anat Sci Educ. 2018;11:478-87.

21. McClurg C, Powelson S, Lang E, Aghajafari F, Edworthy S. Evaluating effectiveness of small group information literacy instruction for undergraduate medical education students using a pre-and post-survey study design. Health Info Libr J. 2015;32:120-30.

22. Levinson M, Kelly D, Zahariou K, Johnson M, Jackman C, Mackenzie S. Description and student self-evaluation of a pilot integrated small group learning and simulation programme for medical students in the first clinical year. Intern Med J. 2017;47:211-6.

23. Jackson D, Hickman LD, Power T, Disler R, Potgieter I, Deek H, et al. Small group learning: graduate health students' views of challenges and benefits. Contemp Nurse. 2014;48:117-28.

24. Elizondo-Omaña RE, Guzmán-López S, García-Rodríguez MD. Dissection as a teaching tool: past, present, and future. Anat Rec B New Anat. 2005;285:11-5.

25. Durán CE, Bahena EN, Rodríguez MD, Baca GJ, Uresti AS, Elizondo-Omaña RE, et al. Near-peer teaching in an anatomy course with a low faculty-to-student ratio. Anat Sci Educ. 2012;5:171-6.

26. Quiroga-Garza A, Elizondo-Omaña RE, Salinas-Alvarez YE, Guzman-Lopez SE. Effective near-peers in anatomy. FASEB J. 2020;34:1.

27. Elizondo-Omaña RE, Zarate-Garza PP, Jacobo-Baca G, Salinas-Alvarez Y Fernandez-Rodarte BA, Martinez-Garza JH, et al. Collaborative mentoring for effective medical research groups. MedEdPublish. 2019;8:1-13.

28. Ross MT, Cameron HS. Peer assisted learning: a planning and implementation framework: AMEE guide no. 30. Med Teach. 2007;29:527-45.

29. Damon W, Phelps E. Critical distinctions among three approaches to peer education. Int J Educ Res. 1989;13:9-19.

30. English R, Brookes ST, Avery K, Blazeby JM, Ben-Shlomo Y. The effectiveness and reliability of peer-marking in first-year medical students. Med Educ. 2006;40:965-72. 